\title{
Efficacy of nickel-titanium memory alloy in the treatment of multiple rib fracture combined with sternal fracture
}

\author{
MING XIONG ${ }^{1}$, WEI HU ${ }^{1}$, QIANG LOU ${ }^{1}$, SHI YIN $^{2}$ and XIN WANG ${ }^{3}$ \\ Departments of ${ }^{1}$ Cardiothoracic Surgery and ${ }^{2}$ ICU, First People's Hospital of Fuzhou, Fuzhou, Jiangxi 344000; \\ ${ }^{3}$ Department of Thoracic Surgery, Xuzhou Central Hospital, Xuzhou, Jiangsu 221000, P.R. China
}

Received January 21, 2019; Accepted May 16, 2019

DOI: $10.3892 / \mathrm{etm} .2019 .7597$

\begin{abstract}
Clinical efficacy and complications of nickel-titanium memory alloy in the treatment of multiple rib fractures combined with sternal fractures was investigated. A retrospective analysis of 123 patients with multiple rib fractures combined with sternal fractures admitted to First People's Hospital of Fuzhou from January 2013 to December 2015 was performed, including study group (treated with internal fixation by the nickel-titanium memory alloy, $n=68$ ) and control group (treated with internal fixation by partial pressure bandage, $n=55$ ). Mean arterial pressure (MAP), heart rate (HR), and visual analogue pain score (VAS) of the two groups before and after treatment were compared and analyzed. No significant difference in MAP, HR and VAS scores between groups was detected before treatment $(\mathrm{P}>0.05)$. After treatment, MAP score of study group was significantly higher, and HR and VAS scores were significantly lower $(\mathrm{P}<0.05)$. Method of internal fixation by the nickel-titanium memory alloy, with better efficacy than the traditional method of internal fixation by partial pressure bandage and less postoperative complications in the treatment of flail chest caused by multiple rib fractures combined with sternal fractures, is worthy of clinical application and promotion.
\end{abstract}

\section{Introduction}

Severe closed chest injury in patients caused by multiple rib and sternal fractures often lead to flail chest (1) which is one of the six main causes of early death caused by thoracic trauma to seriously endanger human life (2). With unsupported thoracic

Correspondence to: Dr Wei Hu, Department of Cardiothoracic Surgery, First People's Hospital of Fuzhou, 421 Gandong Avenue, Fuzhou, Jiangxi 344000, P.R. China

E-mail: ukq32e@163.com

Key words: nickel-titanium memory alloy, multiple rib fracture combined with sternal fracture, clinical efficacy, complications, flail chest wall due to fractured ribs, and critical clinical symptoms such as abnormal respiratory, induced acute respiratory distress syndrome or multiple organ failure, patients with flail chest usually are hard to cure, thus suffering from a high mortality rate (3-5).

At present, stent traction, simple partial pressure bandage or internal fixation by partial pressure bandage assisted by ventilator are the main treatments for the flail chest caused by multiple rib fractures (6). However, after the above conservative treatments, patients often suffer from accumulated secretions in the respiratory tract, chest pain, tachypnea, and even dyspnea aroused from too long bed rest that will increase the risk of parenchymatous pneumonia such as acute pneumonia and persistent pneumonia, and also suffer from muscular atrophy due to easily occurring incomplete transposition or complete fractures, vulnerable to complications or recurrence of disease after treatment $(7,8)$. With the innovation of medical technology and the advanced internal fixer with better performance, the nickel-titanium memory alloy internal fixer, has high safety, stability, maneuverability and convenience, which is able to narrow the wound, is a new type of treatment device for the flail chest $(9,10)$. So far few studies on the efficacy of the method of internal fixation by the nickel-titanium memory alloy and the method of internal fixation by the partial pressure bandage in treating the flail chest caused by multiple rib fractures combined with sternal fractures have been reported, which inspired this study to investigate the efficacy of these two methods in the treatment of patients with multiple rib fractures combined with sternal fractures and make comparison of the postoperative adverse reactions and complications between the two methods.

\section{Patients and methods}

Patient information. This study retrospectively analyzed 123 patients with multiple rib and sternal fractures admitted to the First People's Hospital of Fuzhou (Fuzhou, China) from January 2013 to December 2015. Among them, 68 patients (43 males and 25 females) treated with internal fixation by the nickel-titanium memory alloy were enrolled in study group, aged 18 to 71 years, with a mean age of $46.63 \pm 5.47$ years; 55 patients (39 males and 16 females) treated with internal 
fixation by partial pressure bandage were enrolled in control group, aged 19 to 73 years, with a mean age of $47.81 \pm 4.37$ years. Inclusion criteria: i) patients diagnosed with multiple rib and sternal fractures; ii) patients with complete medical records; iii) patients older than 18 years; and iv) patients with no relevant treatment history in other hospitals. Exclusion criteria: i) patients unwilling to cooperate with the medical care; ii) patients who were transferred to other hospitals or died during the hospitalization; iii) patients with other respiratory diseases; iv) patients with acute gastrointestinal bleeding; v) patients with cardiac, mediastinal and macrovascular injuries; vi) patients with one or more tumors; and vii) patients with mental disorders and cognitive impairment. All the study subjects and their families signed an informed consent and cooperated with medical staff to complete the relevant medical treatment.

The study was approved by the Ethics Committee of First People's Hospital of Fuzhou. Patients who participated in this research had complete clinical data. The signed informed consents were obtained from the patients or the guardians.

Methods. PROSIM8 monitor made by Fluke Corporation (Everett, WA, USA) was connected to all patients after the admission to monitor their mean arterial pressure (MAP) and heart rate (HR). In control group treated with internal fixation by partial pressure bandage, first the drainage treatment was performed to prevent pneumothorax, then the chest wall was compressed by the fixed sterilized cotton pad, after that the ventilator was used with positive end expiratory pressure at 6-8 mmHg of oxygen. In study group, under the general anesthesia, the relevant ribs were fixed with method of key-point fixation according to the support conditions of the thoracic. After reduction of fractured ribs, the appropriate type of nickel-titanium memory alloy embracing device (Lanzhou Seemine SMA Co., Ltd., Lanzhou, China) was fixed to the fractured ribs. After fixation was well done, closed drainage tube was routinely placed. Then, comparison was performed between the two groups in terms of efficacy, hemodynamics, visual analogue pain score (VAS), and occurrence rate of adverse reactions 5 days after treatment, and hospitalization time.

Evaluation criteria. Efficacy evaluation criteria (11): i) Significant efficacy: normal clinical symptoms, physical signs and imaging examination results; ii) certain efficacy: improved clinical symptoms and physical signs, with slightly abnormal imaging examination results; iii) stable condition: no obviously relieved clinical symptoms and physical signs, with unchanged imaging examination results; iv) no efficacy: unusually aggravated clinical symptoms and physical signs, with abnormal imaging examination results. Clinical overall efficiency $=$ (number of patients with significant efficacy + number of patients with certain efficacy)/total number of cases $\mathrm{x} 100 \%$.

VAS assessment criteria (12): VAS score ranged from 0-10 points, higher the score, higher the patient's pain index.

Statistical analysis. Statistical analysis was carried out using SPSS19.1 software system (IBM Corp., Armonk, NY, USA).
Count data were expressed as the percentage [n (\%)]. Difference between two groups was measured by $\chi^{2}$ test. Measurement data were expressed as mean \pm standard deviation (SD). Difference between two groups was compared by t-test, so was the difference between the conditions before and after treatment in one group. $\mathrm{P}<0.05$ was considered to indicate a statistically significant difference.

\section{Results}

Comparison of the clinical data of patients in the two groups. To ensure accuracy and credibility of experimental results, patients selected into the two groups were not statistically different in basic clinical such as sex, age, weight, type of sternal fracture, location of sternal fracture and cause of injury. There was no statistical significance $(\mathrm{P}>0.05)$, indicating that the two groups of patients were comparable. See Table I for details of patients' basic information.

Comparison of MAP between study and control group before and after admission to hospital. No significant difference in MAP between the two groups was shown before treatment $(\mathrm{P}>0.05)$. After treatment, MAP of the study group was statistically significantly higher than that of control group $(\mathrm{P}<0.05)$. MAPs in both study and control group after treatment were higher than those before treatment, with difference being statistically significant $(\mathrm{P}<0.05$; Table II).

Comparison of HR between study and control group before and after admission to hospital. No significant difference in the HR between the two groups was shown before treatment $(\mathrm{P}>0.05)$. After treatment, HR of study group was statistically significantly lower than that of control group $(\mathrm{P}<0.05)$. HRs in both study and control group after treatment were lower than those before treatment, with statistical difference between them $(\mathrm{P}<0.05$; Table III).

Comparison of VAS between study and control group before and after admission to hospital. No significant difference in VAS between the two groups was shown before treatment (P>0.05). After treatment, VAS of study group was statistically significantly lower than that of control group $(\mathrm{P}<0.05)$. VAS scores in both study and control groups after treatment were lower than those before treatment, and difference was statistically significant $(\mathrm{P}<0.05$; Table IV).

Comparison of hospitalization time between study and control group. Hospitalization time of study group (18.63 \pm 2.17 days) was much lower than that of control group (24.28 \pm 3.62 days), and the two were statistically different $(\mathrm{t}=10.71, \mathrm{P}<0.001$; Fig. 1).

Comparison of efficacy between study and control group. The overall effective rate of study group was much higher than that of control group, and difference was statistically significant $(\mathrm{P}<0.05$; Table V).

Comparison of occurrence of complications and adverse reactions in study and control group. The number of patients with pulmonary infection in study group was significantly 
Table I. Basic information of patients in study and control group [n (\%)].

\begin{tabular}{|c|c|c|c|c|}
\hline Group & Study $(n=68)$ & Control $(n=55)$ & $\chi^{2}$ & P-value \\
\hline Sex & & & 0.806 & 0.369 \\
\hline Male & $43(63.24)$ & $39(70.91)$ & & \\
\hline Female & $25(36.76)$ & $16(29.09)$ & & \\
\hline Age (year) & & & 3.128 & 0.077 \\
\hline$\leq 45$ & $29(42.65)$ & $15(27.27)$ & & \\
\hline$>45$ & $39(57.35)$ & $40(72.73)$ & & \\
\hline Weight (kg) & & & 0.194 & 0.660 \\
\hline$\leq 60$ & $27(39.71)$ & $24(43.64)$ & & \\
\hline$>60$ & $41(60.29)$ & $31(56.36)$ & & \\
\hline Type of sternal fracture & & & 0.387 & 0.534 \\
\hline Transverse fracture & $31(45.59)$ & $22(40.00)$ & & \\
\hline Oblique fracture & $37(54.41)$ & $33(60.00)$ & & \\
\hline Location of sternal fracture & & & 0.262 & 0.755 \\
\hline Gladiolus & $50(73.53)$ & $40(72.73)$ & & \\
\hline Manubrium & $13(19.12)$ & $9(16.36)$ & & \\
\hline Sternal angle & $5(7.35)$ & $6(10.91)$ & & \\
\hline Cause of injury & & & 0.650 & 0.723 \\
\hline Traffic & $54(79.41)$ & $43(78.18)$ & & \\
\hline Blunt & 8 (11.76) & $5(9.09)$ & & \\
\hline Falling & $6(8.82)$ & $7(12.73)$ & & \\
\hline
\end{tabular}

Table II. Comparison of MAP between study and control group before and after admission to hospital (mmHg).

\begin{tabular}{lccr}
\hline Index & Study group $(\mathrm{n}=68)$ & Control group $(\mathrm{n}=55)$ & $\mathrm{t}$ \\
\hline Before treatment & $83.95 \pm 13.38$ & $83.68 \pm 12.79$ & 0.114 \\
After treatment & $117.83 \pm 15.36$ & $99.23 \pm 14.47$ & 6.852 \\
$\mathrm{t}$ & 13.72 & 5.971 & $<0.001$ \\
P-value & $<0.001$ & $<0.001$ & \\
\hline
\end{tabular}

MAP, mean arterial pressure.

Table III. Comparison of HR between study and control group before and after admission to hospital (beat/min).

\begin{tabular}{lccr}
\hline Index & Study group $(\mathrm{n}=68)$ & Control group $(\mathrm{n}=55)$ & $\mathrm{t}$ \\
\hline Before treatment & $115.21 \pm 10.35$ & $116.39 \pm 11.12$ & 0.608 \\
After treatment & $84.62 \pm 8.24$ & $102.51 \pm 9.28$ & 11.31 \\
t & 19.070 & 7.107 & $<0.001$ \\
P-value & $<0.001$ & $<0.001$ & \\
\hline
\end{tabular}

HR, heart rate.

lower than that of control group, with a recognized statistical difference $(\mathrm{P}<0.05)$. The number of patients with adverse reactions such as atelectasis and sternal malformation in study group was smaller than that in control group, but they were not statistically different $(\mathrm{P}>0.05$; Table VI).

\section{Discussion}

Multiple rib fractures, a kind of closed injuries in thoracic surgery, often occurs in severe traffic accidents or severe crush injuries $(13,14)$. According to Yang et al $(15)$, mortality rate of 
Table IV. Comparison of the VAS between study and control group before and after admission to hospital.

\begin{tabular}{lccr}
\hline Group & Study $(\mathrm{n}=68)$ & Control $(\mathrm{n}=55)$ & $\mathrm{t}$ \\
\hline Before the treatment & $7.65 \pm 2.21$ & $7.48 \pm 2.48$ & 0.402 \\
After the treatment & $2.14 \pm 0.86$ & $3.74 \pm 1.13$ & 8.915 \\
$\mathrm{t}$ & 19.160 & 17.360 & $<0.001$ \\
P-value & $<0.001$ & $<0.001$ & \\
\end{tabular}

VAS, visual analogue pain score.

Table V. Comparison of the efficacy between study and control group [n (\%)].

\begin{tabular}{lcccc}
\hline Effective degree & Study $(\mathrm{n}=68)$ & Control $(\mathrm{n}=55)$ & $\chi^{2}$ & P-value \\
\hline Significant efficacy & $11(16.18)$ & $8(14.55)$ & 0.062 & 0.804 \\
Certain efficacy & $47(69.12)$ & $30(54.55)$ & 2.758 & 0.097 \\
Stable situation & $7(10.29)$ & $11(20.00)$ & 2.293 & 0.130 \\
No efficacy & $3(4.41)$ & $6(10.91)$ & 1.893 & 0.169 \\
Overall effective rate & $58(85.29)$ & $38(69.09)$ & 4.660 & 0.031 \\
\hline
\end{tabular}

Table VI. Comparison of the occurrence of complications and adverse reactions in study and control group [n (\%)].

\begin{tabular}{lcccr}
\hline Group & Study $(\mathrm{n}=68)$ & Control $(\mathrm{n}=55)$ & $\chi^{2}$ & P-value \\
\hline Pulmonary infection & $5(7.35)$ & $11(20.00)$ & 4.298 & 0.038 \\
Atelectasis & $1(1.47)$ & $4(7.27)$ & 2.625 & 0.105 \\
Sternal malformation & $3(4.41)$ & $5(9.09)$ & 1.095 & 0.295 \\
Others & $2(2.94)$ & $6(10.91)$ & 3.175 & 0.075 \\
\hline
\end{tabular}

the flail chest is approximately $16 \%$ which is increased if the flail chest is combined with a sternal fracture (16). Industry stepping into the advanced stage, multiple rib fractures combined with sternal fractures, with a rocketing growth of incidence rate and severe damage to human health, have become the focus of modern medicine $(9,17)$. The advancement of the new internal fixation equipment makes the operation of patients with fractures easier and safer, for example, the nickel-titanium memory alloy, with its good histocompatibility to be deformed and deployed at low temperature and to automatically restore the original shape at body temperature, is of great help for the convenience of the fixation, the shortening of the operation time, the decrease of injuries around the fracture, and the maintenance of effective blood circulation. Different arced embracing device are chosen according to different fraction sties. The embracing device, which can fix the ribs at multiple points and collectively surround the rib to generate the embracing force, is able to make it harder for the fracture end to rotate and shift, and cause no obvious adverse reactions to the human body, thus meeting the requirements of the implant materials for human body $(18,19)$. Two methods were studied of internal fixation by the nickel-titanium memory alloy and by the partial pressure bandage in treating patients with multiple rib fractures and sternal fractures, and analyzed the difference between the two groups in terms of the hospitalization time,

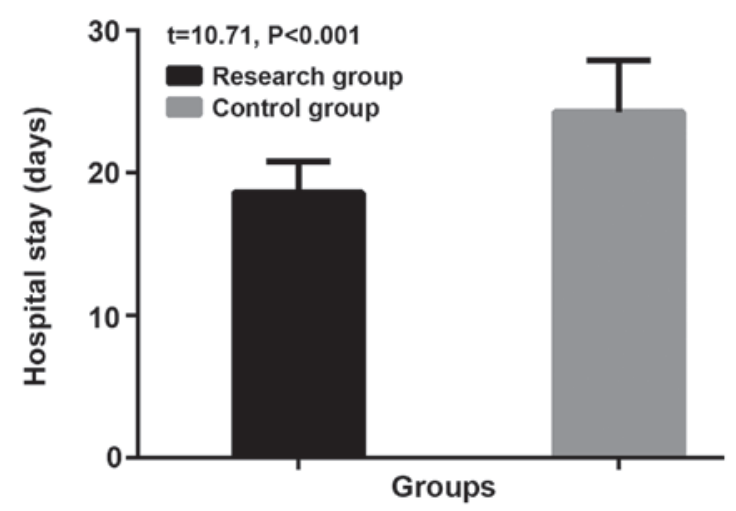

Figure 1. Comparison of hospitalization time between study and control group. Hospitalization time in study group (18.63 \pm 2.17 days) was much shorter than that in control group (24.28 \pm 3.62 days), and the two groups were statistically different $(\mathrm{t}=10.71, \mathrm{P}<0.001)$.

efficacy, occurrence rate of postoperative complications, and the MAP, HR and VAS scores before and after the treatment, to provide effective reference and guidance for the future treatment of the disease.

Results of this study showed no significant difference in MAP and HR between the two groups before treatment, but revealed statistical difference after treatment that the 
MAP and HR indexes in study group were in greatly better conditions than those in control group, thus, after treatment, MAP in study group was higher than that in control group, while HR in study group was lower than that in control group, and differences were statistically significant. In study group, where the patients were treated with internal fixation by the nickel-titanium memory alloy to get the dislocated ribs and sternal fractures reset and internally fixed, the deformed thorax of the patient was restored to its original shape and function, and abnormal breathing disorder and compressive cardiac tamponade of the patient were eliminated (20), with more pleasing MAP, HR indicators, postoperative efficacy, and incidence of chest deformity compared to control group and that before treatment. In control group, non-operative treatment brought no complete relief to the patient's abnormal breathing and caused different degrees of softening, collapse, and instability of sternal wall that added severe pain to the even slight movement of patients (21), with a statistically significantly higher VAS score than that of study group. Some literature reported that the needs for analgesia between patients treated with rib fracture surgery and non-surgical patients were not different before treatment, but after treatment, patients who underwent surgery required fewer analgesics than non-surgical patients (22). With internal fixation, patients in study group had free movement and sputum, which is conducive to the maintenance of a clear airway to reduce the incidence of postoperative pulmonary infection and atelectasis (23); while in the control group, patients might suffer from respiratory muscle atrophy with the use of the ventilator, and were incapable of timely sputum excretion due to severe pain or inconvenient movement, prone to atelectasis and repeated pulmonary infection (24), which contributed to longer hospitalization time and more cases of pulmonary infection and atelectasis in control group than study group. Study by Zhang et al (25) proved that patients who underwent surgical treatment of flail chest and pulmonary contusion enjoyed a shorter hospitalization time than non-surgical patients, which agrees with the results of this study.

Shortcomings of this experiment surfaced due to limited experimental conditions, for example, the sample size of the research objects was small for statistical analysis, furthermore, the possible differences in different ethnic groups were not studied. A longer-term follow-up survey is also required.

In summary, the clinical efficacy of the internal fixation by the nickel-titanium memory alloy for the treatment of multiple rib fractures and sternal fractures was better than the traditional method of partial pressure bandage, with fewer postoperative complications, which is worthy of clinical application and promotion.

\section{Acknowledgements}

Not applicable.

\section{Funding}

No funding was received.

\section{Availability of data and materials}

The datasets used and/or analyzed during the present study are available from the corresponding author on reasonable request.

\section{Authors' contributions}

MX, WH and QL conceived and designed the study. MX, WH, SY and XW were responsible for the data collection and analysis. MX and QL were in charge of interpreting the data and drafting the manuscript. WH and SY made revisions from critical perspective for important intellectual content. The final version was read and approved by all authors.

\section{Ethics approval and consent to participate}

The study was approved by the Ethics Committee of First People's Hospital of Fuzhou (Fuzhou, China). Patients who participated in this research had complete clinical data. The signed informed consents were obtained from the patients or the guardians.

\section{Patient consent for publication}

Not applicable.

\section{Competing interests}

The authors declare that they have no competing interests.

\section{References}

1. Schulz-Drost S, Oppel P, Grupp S, Krinner S, Langenbach A, Lefering $R$ and Mauerer A: Bony injuries of the thoracic cage in multiple trauma: Incidence, concomitant injuries, course and outcome. Unfallchirurg 119: 1023-1030, 2016 (In German).

2. Coughlin TA, Ng JW, Rollins KE, Forward DP and Ollivere BJ: Management of rib fractures in traumatic flail chest: A meta-analysis of randomised controlled trials. Bone Joint J 98-B: 1119-1125, 2016.

3. de Campos JRM and White TW: Chest wall stabilization in trauma patients: Why, when, and how? J Thorac Dis 10 (Suppl 8): S951-S962, 2018.

4. Wetterau LM, Smith-Singares E, Bilfinger T, Vosswinkel J, Shapiro MJ and Dagum AB: Management of pulmonary hernia through a flail segment in closed thoracic trauma using open reduction, internal fixation and pectoralis major flap reconstruction: a case report. Can J Plast Surg 19: 145-147, 2011.

5. Nickerson TP, Thiels CA, Kim BD, Zielinski MD, Jenkins DH and Schiller HJ: Outcomes of complete versus partial surgical stabilization of flail chest. World J Surg 40: 236-241, 2016.

6. Marasco SF, Davies AR, Cooper J, Varma D, Bennett V, Nevill R, Lee G, Bailey M and Fitzgerald M: Prospective randomized controlled trial of operative rib fixation in traumatic flail chest. J Am Coll Surg 216: 924-932, 2013.

7. Pieracci FM, Lin Y, Rodil M, Synder M, Herbert B, Tran DK, Stoval RT, Johnson JL, Biffl WL, Barnett CC, et al: A prospective, controlled clinical evaluation of surgical stabilization of severe rib fractures. J Trauma Acute Care Surg 80: 187-194, 2016.

8. Dehghan N, de Mestral C, McKee MD, Schemitsch EH and Nathens A: Flail chest injuries: a review of outcomes and treatment practices from the National Trauma Data Bank. J Trauma Acute Care Surg 76: 462-468, 2014.

9. Qiu M, Shi Z, Xiao J, Zhang X, Ling S and Ling H: Potential benefits of rib fracture fixation in patients with flail chest and multiple non-flail rib fractures. Indian J Surg 78: 458-463, 2016.

10. Broadhurst J, Moorjani N and Ohri S: Traumatic fracture of nitinol thermoreactive sternal clips. Interact Cardiovasc Thorac Surg 10: 465-466, 2010. 
11. Billè A, Okiror L, Karenovics W and Routledge T: Experience with titanium devices for rib fixation and coverage of chest wall defects. Interact Cardiovasc Thorac Surg 15: 588-595, 2012.

12. Boonstra AM, Schiphorst Preuper HR, Balk GA and Stewart RE: Cut-off points for mild, moderate, and severe pain on the visual analogue scale for pain in patients with chronic musculoskeletal pain. Pain 155: 2545-2550, 2014.

13. Schulte K, Whitaker D and Attia R: In patients with acute flail chest does surgical rib fixation improve outcomes in terms of morbidity and mortality? Interact Cardiovasc Thorac Surg 23 314-319, 2016.

14. Schulz-Drost S, Grupp S, Pachowsky M, Oppel P, Krinner S, Mauerer A, Hennig FF and Langenbach A: Stabilization of flail chest injuries: minimized approach techniques to treat the core of instability. Eur J Trauma Emerg Surg 43: 169-178, 2017.

15. Yang $\mathrm{H}$, Tantai $\mathbf{J}$ and Zhao $\mathrm{H}$ : Clinical experience with titanium mesh in reconstruction of massive chest wall defects following oncological resection. J Thorac Dis 7: 1227-1234, 2015.

16. Oyetunji TA, Jackson HT, Obirieze AC, Moore D, Branche MJ, Greene WR, Cornwell EE III and Siram SM: Associated injuries in traumatic sternal fractures: A review of the National Trauma Data Bank. Am Surg 79: 702-705, 2013.

17. Schulz-Drost S, Krinner S, Langenbach A, Oppel P, Lefering R, Taylor D, Hennig FF and Mauerer A; TraumaRegister DGU: Concomitant sternal fracture in flail chest: an analysis of 21,741 polytrauma patients from the TraumaRegister DGU ${ }^{\circledR}$. Thorac Cardiovasc Surg 65: 551-559, 2017.

18. Yan Z, Liang Y,Fang Y, Yao X, Ma K and Huang F: Biomechanical study of nickel-titanium three-dimensional memory alloy mesh and autologous bone in treatment of canine tibial plateau collapse fracture. Zhongguo Xiu Fu Chong Jian Wai Ke Za Zhi 32: 722-725, 2018 (In Chinese).
19. Li H, Mao Y, Qu X, Zhao X, Dai K and Zhu Z: Nickel-titanium shape-memory sawtooth-arm embracing clamp for complex femoral revision hip arthroplasty. J Arthroplasty 31: 850-856, 2016.

20. Wu WM, Yang Y, Gao ZL, Zhao TC and He WW: Which is better to multiple rib fractures, surgical treatment or conservative treatment? Int J Clin Exp Med 8: 7930-7936, 2015.

21. Schuurmans J, Goslings JC and Schepers T: Operative management versus non-operative management of rib fractures in flail chest injuries: A systematic review. Eur J Trauma Emerg Surg 43: 163-168, 2017.

22. Leinicke JA, Elmore L, Freeman BD and Colditz GA: Operative management of rib fractures in the setting of flail chest: a systematic review and meta-analysis. Ann Surg 258: 914-921, 2013.

23. Zhao X, Zhu ZA, Sun YH, Wang Y,Zhao J,Zhang YJ and Dai KR: Nickel-titanium shape-memory sawtooth-arm embracing fixator for periprosthetic femoral fractures. Int Orthop 36: 619-626, 2012.

24. De Palma A, Sollitto F, Loizzi D, Di Gennaro F, Scarascia D, Carlucci A, Giudice G, Armenio A, Ludovico R and Loizzi M: Chest wall stabilization and reconstruction: short and long-term results 5 years after the introduction of a new titanium plates system. J Thorac Dis 8: 490-498, 2016.

25. Zhang Y, Tang X, Xie H and Wang RL: Comparison of surgical fixation and nonsurgical management of flail chest and pulmonary contusion. Am J Emerg Med 33: 937-940, 2015.

This work is licensed under a Creative Commons Attribution-NonCommercial-NoDerivatives 4.0 International (CC BY-NC-ND 4.0) License. 